\title{
Pathology of a unique type of teratoid medulloepithelioma
}

\author{
JOHN HARRY AND GWYN MORGAN \\ From the Department of Pathology, Institute of Ophthalmology, University of London
}

SUMMARY A unique teratoid medulloepithelioma showing a conspicuous vascular component with orbital involvement is described.

\section{Case report}

CLINICAL HISTORY

A 6-week-old male infant was referred to the Eye Department at Barnsley District General Hospital because of a buphthalmic right eye, present since birth. A retinoblastoma was suspected on clinical examination, and the eye was removed and sent to the Department of Pathology at the Institute of Ophthalmology, London. The remaining eye was normal, and the baby was otherwise apparently fit and healthy.

\section{PATHOLOGICAL EXAMINATION}

Naked eye examination revealed a buphthalmic globe with an ectatic limbus inferiorly. A mass was present outside the eye posteriorly below the optic nerve; the iris appeared atrophic. On opening the globe it was noted that the lens was small, there was choroidoretinal atrophy, and the optic nerve head was cupped. No obvious intraocular tumour was apparent.

Histopathological study, however, revealed neoplastic tissue infiltrating the uvea on one side over a wide area, extending from the iris and ciliary body anteriorly to the posterior pole (Fig. 1). Anteriorly, papillary and tubular structures with the formation of large cystic spaces lined by primitive epithelium were seen (Fig. $2 a$ and $b$ ). The stroma was filled with proliferating endothelial cells and there were vascular channels of various sizes, but on the whole small. This tissue had the features of an infantile angioma. There was infiltration of this vascular element through the sclera, and an extraocular angiomatous mass lay posteriorly (Figs. 3 and 4).

There were no histological features to suggest

Address for reprints: Dr John Harry, Department of Pathology, Institute of Ophthalmology, Judd Street, London WC1H 9QS

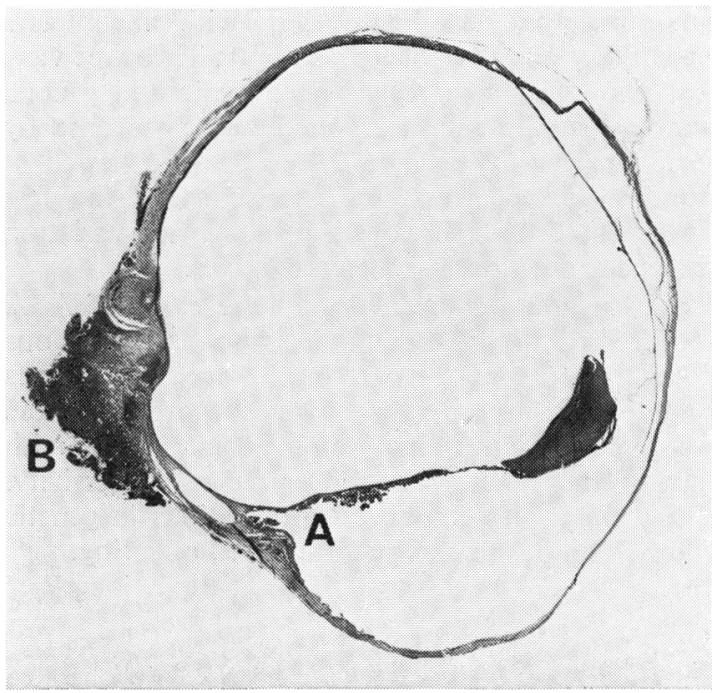

Fig. 1 Section of globe showing neoplastic infiltration of uvea on 1 side $(A)$ and an extraocular mass posteriorly (B). There is artefactual displacement of the lens, and of the iris, ciliary body, and choroid on the affected side.

$H$. and $E$., $\times 2.5$

malignancy, but tumour extended to the cut edge, and removal of the orbital component was obviously incomplete. In view of this, and of the infiltrative nature of the lesion, a close follow-up of the case was recommended to the clinician.

\section{DIAGNOSIS}

Teratoid medulloepithelioma exhibiting a vascular component and with orbital involvement.

\section{Discussion}

As was suggested by Zimmerman (1970), tumours of the non-pigmented ciliary epithelium are divided 
Fig. 2 Neoplastic infiltration of uveal tissue showing cystic area lined by primitive epithelium exhibiting papillary formation.

(a) H. and E., $\times 50$

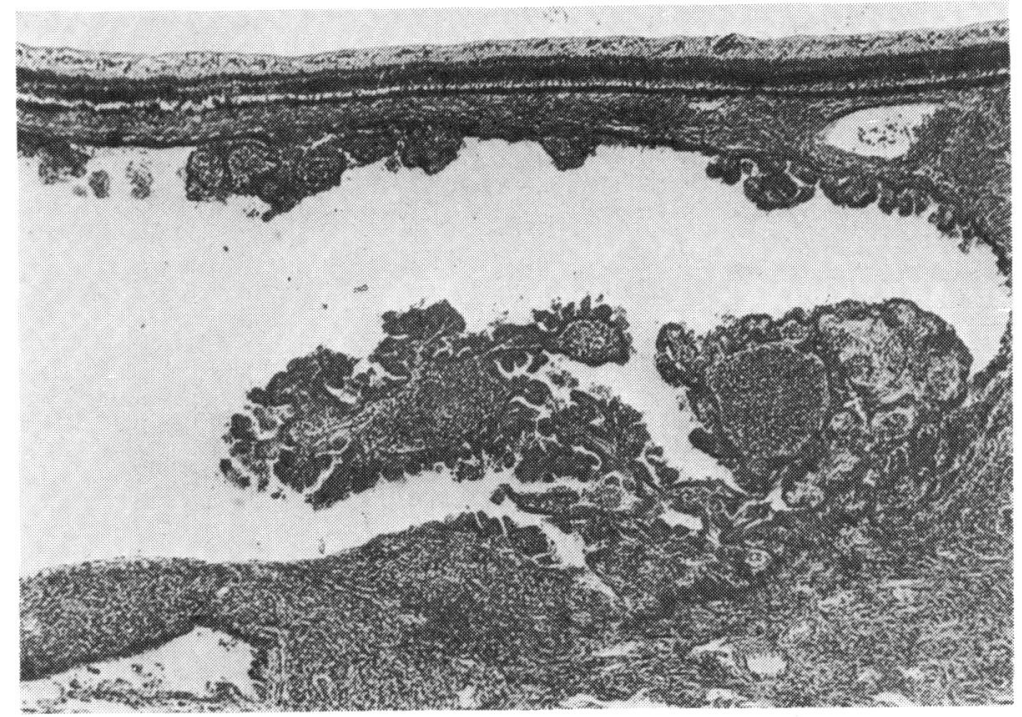

(b) H. and E., $\times 120$

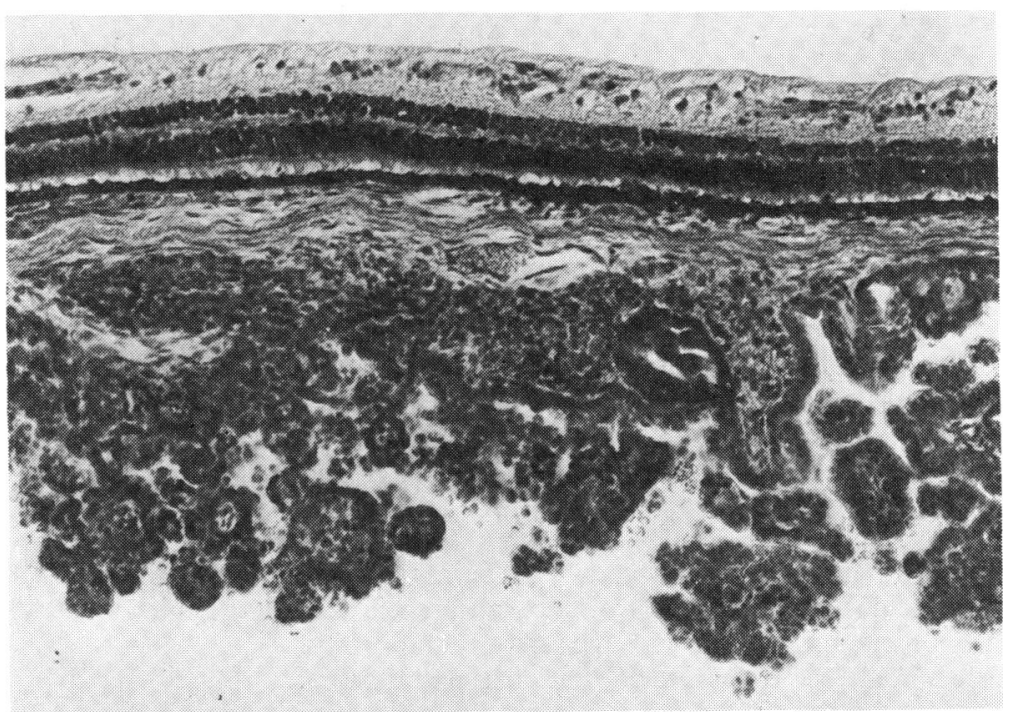

primarily into 2 main groups, namely the embryonal or congenital, and the adult or acquired. Both the benign and malignant varieties of 'pure' and 'teratoid' medulloepitheliomata can be regarded as congenital neoplasms.

The pure type of medulloepithelioma is characterised by the formation of multilayered sheets of undifferentiated cells similar to the primitive medullary epithelium of the optic vesicle. Tubular and papillary structures resembling ciliary epithelium are also formed, and there may in addition be rosette formation, pigment epithelium formation, and differentiation into astrocytic ele- ments. The presence of undifferentiated sheets of neuroblastic cells as seen in retinoblastomata is observed in the malignant varieties of such tumours. Teratoid medulloepitheliomata contain, in addition to the medulloepitheliomatous components, heteroplastic elements, most notably cerebral tissue, hyaline cartilage, and skeletal muscle, which are not normally found in the eye during either embryonic or postnatal development.

The case presented is unique in that while the tumour can be classified as a teratoid medulloepithelioma the presence of a conspicuous vascular element resembling an infantile angioma with 


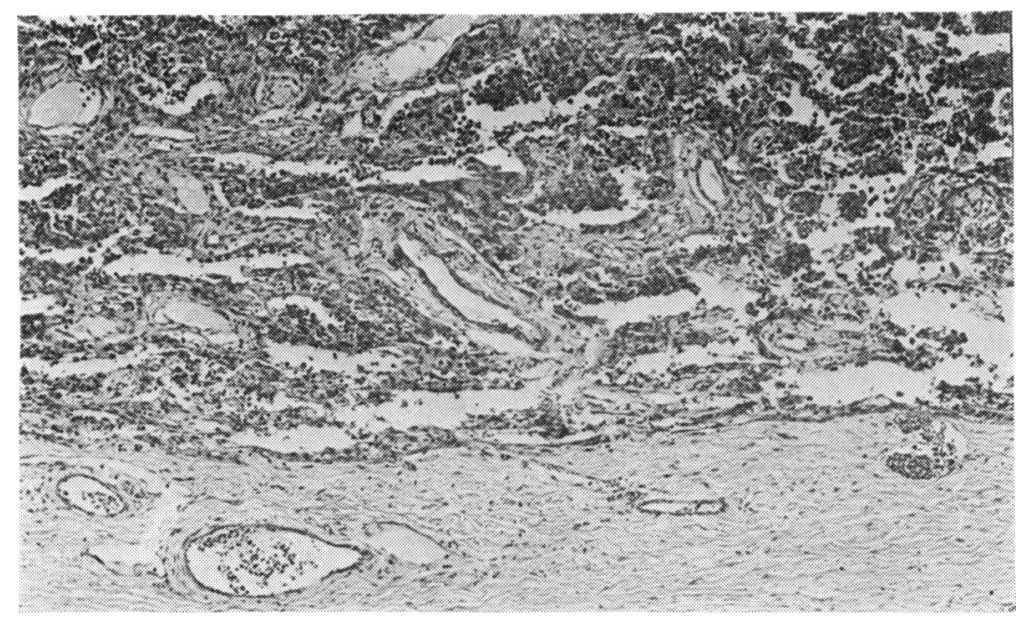

Fig. 3 Section through sclera and extraocular tumour mass. $H$. and $E$., $\times 60$

Fig. 4 Extraocular angiomatous tumour mass. $H$. and $E ., \times 150$

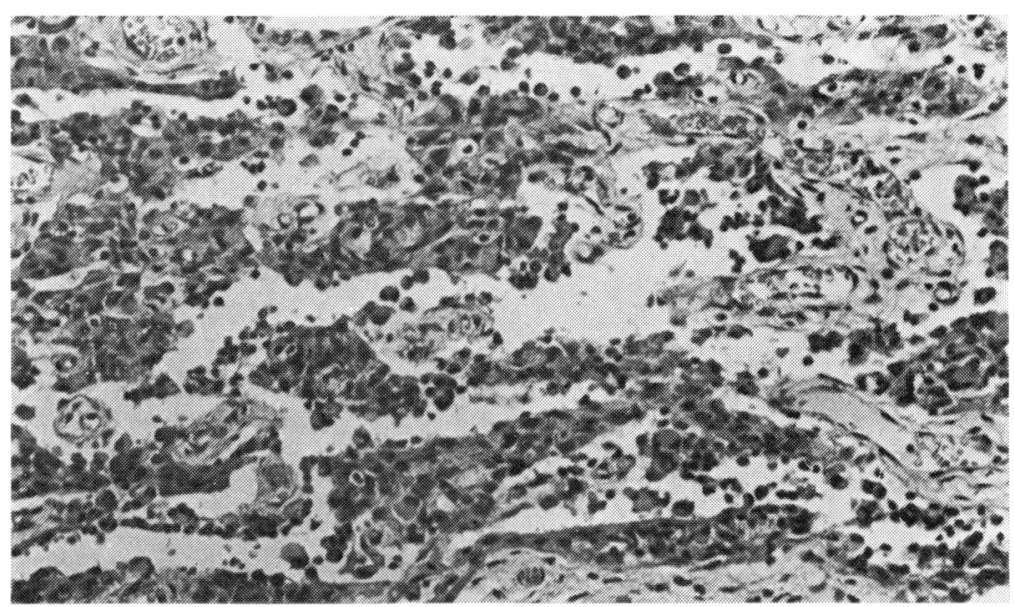

orbital involvement is as far as can be ascertained the first documented report of such an association. It is of interest to speculate that if only the orbital tissue had been submitted for histopathological examination the diagnosis made would have been one of infantile angioma; the presence of a teratoid medulloepithelioma was not suspected until the enucleated eye was fully examined. Zimmerman (1971) has pointed out that a sarcomatous orbital tumour may possibly have originated within the eye, and he cited the example of a chondrosarcomatous neoplasm in the orbit following enucleation of the eye for presumed retinoblastoma. The malignant orbital lesion was considered retrospectively to be part of a teratoid medulloepithelioma, and although there is no histological evidence of malignancy in the case described in this presentation the association of orbital and ocular involvement is not dissimilar.

We wish to thank Mr A. K. Mandal of Barnsley District General Hospital for providing the clinical information, Mr V. J. Elwood and Mr I. Rhodes of the Department of Pathology, Institute of Ophthalmology, for technical assistance, the staff of the Department of Audio-Visual Communications for developing and printing the photomicrographs, and Mrs Audrey Wood for secretarial help.

\section{References}

Zimmerman, L. E. (1970). The remarkable polymorphism of tumours of the ciliary epithelium. Transactions of the Australian College of Ophthalmologists, 2, 114-125.

Zimmerman, L. E. (1971). Verhoeff's 'Terato-Neuroma'. A critical reappraisal in light of new observations and current concepts in embryonic tumours. American Journal of Ophthalmology, 72, 6, 1039-1057. 